ISSN: $1130-3743$

\title{
EL DESARROLLO CÍVICO COMO OBJETIVO. UNA PROPUESTA PEDAGÓGICA
}

\section{The civic development as an aim. A pedagogical proposal}

\section{Le développement civique comme finalité. Une proposition pédagogique}

José Manuel Touriñán LóPEZ

Universidad de Santiago de Compostela. Facultad de Ciencias de la Educación.

Departamento de Teoría e Historia de la Educación. Campus Sur, s/n. 15782 Santiago de Compostela. Correo-e: josemanuel.tourinan@usc.es

Fecha de recepción: enero de 2009

Fecha de aceptación definitiva: abril de 2009

Biblid [(1130-3743) 21, 1, 2009, 129-159]

RESUMEN

La educación cívica y la educación política forman parte de los fines de la educación. Ambas finalidades tienen relación con los conceptos de convivencia y ciudadanía. En este artículo analizamos la necesidad de cualificar y especificar la convivencia con objeto de determinar las condiciones propias de una propuesta pedagógica: el desarrollo ć́vico como responsabilidad compartida y derivada de formación. Esta propuesta hace posible entender la educación para la convivencia ciudadana como un ejercicio de educación en valores orientado al uso y construcción de experiencia axiológica relativa al desarrollo cívico en un entorno social y personal de interacción, culturalmente diverso.

Palabras clave: educación cívica, educación en valores, convivencia pacífica, convivencia ciudadana, educación política, desarrollo cívico. 
SUMMARY

The civic education and political education are part of the educational aims. Both goals are related to the concepts of coexistence and citizenship. In this article we analyze the need to qualify and specify the concept of coexistence in order to determine the conditions of an educational proposal: civic development as a shared and derived responsibility from formation. This proposal makes it possible to understand education for citizenship as an education in values exercise, oriented to use and build the axiological experience on civic development in an environment of social and personal interaction, culturally diverse.

Key words: civic education, education in values, pacific coexistence, citizen coexistence, political education, civic development.

\section{SOMMAIRE}

L'éducation civique et l'éducation politique font partie de les finalités de l'éducation. Ces deux bouts sont liés aux concepts de la coexistence et de la citoyenneté. Dans cet article, nous analysons la nécessité de qualifier et spécifier le concept de coexistence afin de déterminer les conditions d'une proposition d'éducation: le développement civique comme une responsabilité partagée et dérivé de la formation. Cette proposition permet de comprendre l'éducation pour la coexistence citoyenne comme un exercice de l'éducation sur valeurs axée à l'utilisation et la construction de l'expérience axiologique sur civique développement dans un environnement social et personnelle pour l'interaction, culturellement diversifié.

Mots clés: éducation civique, éducation dans des valeurs, coexistence pacifique, coexistence des citoyens, éducation politique, développement civique.

\section{INTRODUCCIÓN}

Construir la convivencia en una sociedad más justa y tolerante es uno de los problemas fundamentales que los hombres y mujeres de hoy debemos afrontar. Hoy es urgente la formación de ciudadanos competentes para convivir en una sociedad plural con las diversas formas de pensar y vivir. La visión de un mundo homogéneo y uniforme ha saltado rota en mil pedazos. Estamos asistiendo a una profunda y rápida transformación global como nunca antes se había conocido. La globalización está afectando en su misma raíz a la sociedad desarrollada y menos desarrollada, a los individuos de una y otra orilla del desarrollo en todos los planos: político, económico, social y cultural. La imagen de una sociedad compacta, estructurada en torno a un sistema de valores coherente y a unos patrones de conducta socialmente compartidos se ha derrumbado, incluso en aquellas poblaciones alejadas de las grandes ciudades. La sociedad hipercomunicada ha roto las fronteras 
y ha abierto espacios de comunicación donde antes sólo había aislamiento y monólogos. En adelante, ya nada será igual: costumbres y tradiciones, lengua y religión, valores y comportamientos, en una palabra, la cultura se verá contrastada con otras formas de vida, que son expresión de otras tantas culturas y reclaman espacios propios, genuinos ámbitos de manifestación de su identidad. Lo uniforme y homogéneo ha dado paso a lo complejo y multicultural (Ortega, Touriñán y Escámez, 2006).

Ante estos cambios, se hace más que nunca imprescindible "aprender a existir", y "aprender a convivir". Esto refuerza el papel de la sociedad civil como agente moral, porque la Sociedad Civil actual tiene un papel de singular importancia en la promoción y fomento de la vida ciudadana. Sociedad civil y ciudadanía son términos asociados y afines, en cuanto se refieren a individuos e instituciones cuyos derechos o deberes están garantizados o exigidos por las leyes de un Estado, o deberían estarlo. Precisamente por eso vamos a hablar de construir desarrollo cívico, como objetivo de formación y propuesta pedagógica, enfatizando la importancia de la participación y la responsabilidad de todos en el desarrollo de competencias para los asuntos sociales en un marco legal territorializado que implica a diversas y plurales organizaciones. Esta tesis se justifica atendiendo a una doble consideración que debe ser analizada y fundamentada: la intervención educativa es un problema de todos y el desarrollo cívico es una responsabilidad de formación.

\section{LA INTERVENCIÓN EDUCATIVA ES UN PROBLEMA DE TODOS}

Vivimos en sociedad y en comunidad y, para que esto sea posible, necesitamos desarrollar y mantener normas de convivencia. Nos organizamos políticamente y actuamos con relación a un patrón cultural determinado, de manera tal que, en nuestro entorno social pluralista y abierto, la positivación de los derechos como derechos constitucionales es una garantía de la organización de la sociedad para la vida en convivencia.

En las sociedades abiertas occidentales, la ciudadanía y la convivencia se han convertido en ejes fundamentales de la educación, porque representan de manera genuina los ámbitos externo e interno de la educación de la responsabilidad con sentido democrático.

En este contexto, la educación debe ser contemplada y, por ello, aprovechada como una experiencia personal de participación y de aportación al conjunto de la sociedad. Los cauces de participación y de acción ciudadana, desde el punto de vista de la intervención pedagógica y la legitimación de medidas, exigen que se genere una responsabilidad social y jurídica compartida hacia el uso y la construcción de experiencia axiológica respecto de la convivencia dentro y fuera de los marcos legales territorializados (Touriñán, 2007).

Se asume como principio que esto exige una comunidad de metas y la viabilidad armónica entre hombres y culturas. La encrucijada de desarrollo para el hombre implica su propia identidad personal, su tierra y su horizonte interrogativo e interpretativo del sentido de la realidad y de la existencia; cada individuo 
afronta como reto la convergencia de pensamiento, palabra y acción, de manera que pueda conjugar en cada acción lo universal, lo próximo-ambiental y lo singularmente personal.

Desde esta perspectiva, se refuerza el sentido de la sociedad civil como un agente moral y el del desarrollo cívico como objetivo prioritario y de responsabilidad compartida en la educación. La propuesta afecta a cada individuo y la decisión del sujeto aparece, de este modo, como una cuestión de derechos y como una cuestión axiológica y de compromiso ético de voluntades personales e institucionales orientado a lograr la convivencia en un mundo mejor en el que la educación es, cada vez más, el instrumento eficaz del desarrollo cívico, es decir, de transformación y adaptación del hombre como ciudadano del mundo, pero localizado (Touriñán, 2008a).

La propuesta aquí formulada se centra en destacar la formación para la convivencia pacífica ciudadana, como una responsabilidad compartida por los diversos agentes de la educación y como una responsabilidad derivada de educación en valores respecto del marco legal territorializado, en el cual el entorno social y personal en el que interaccionamos es culturalmente diverso. Ahora bien, mantener esta propuesta exige entender en el punto de partida de la argumentación que la intervención educativa y la intervención pedagógica no significan exactamente lo mismo.

\subsection{Intervención educativa e intervención pedagógica no se confunden}

La intervención educativa es la acción intencional para la realización y el logro del desarrollo integral del educando. La intervención educativa tiene carácter teleológico: existe un sujeto agente (educando-educador), existe el lenguaje propositivo (se realiza una acción para lograr algo), se actúa en orden a lograr un acontecimiento futuro (la meta) y los acontecimientos se vinculan intencionalmente. La intervención educativa se realiza mediante procesos de autoeducación y heteroeducación, ya sean estos últimos formales, no formales o informales. La intervención educativa exige respetar la condición de agente en el educando. La acción (cambio de estado que un sujeto hace que acaezca) del educador debe dar lugar a una acción del educando y no sólo a un acontecimiento (cambios de estado que acaecen a un sujeto en una ocasión).

A su vez, la intervención pedagógica es la acción intencional que desarrollamos en la tarea educativa en orden a realizar con, por y para el educando los fines y medios que se justifican con fundamento en el conocimiento de la educación y del funcionamiento del sistema educativo. La intencionalidad reside en la conducta; y ver una conducta como intencional es comprenderla como un conjunto de actuaciones implicadas, por lo que el propio agente cree, en la consecución de algo (Von Wright, 1979). El proceso de intervención pedagógica podría esquematizarse así: "A" (agente educador) hace "X" (lo que el conocimiento científico-tecnológico 
de la educación explica y justifica) para conseguir el resultado "R" (que "B" -agente educando- efectúe las conductas "Y" - explicitadas en la intervención pedagógica de "A»- y alcance el objetivo "Z" - destreza, hábito, actitud o conocimiento educativo-) (Touriñán, 1997).

Intervención educativa e intervención pedagógica no se identifican necesariamente. No todo tipo de intervención educativa requiere el mismo nivel de competencia técnica: un padre educa; un sujeto puede autoeducarse; existen procesos de educación informal. En todos estos procesos se alcanzan resultados educativos, pero es muy probable que la competencia técnica (pedagógica) no tenga en estos casos el nivel necesario para controlar el proceso o decidir acerca de mejores formas de intervención, que es consubstancial a la intervención pedagógica. Intención educativa e intención pedagógica no se identifican necesariamente.

El profesional de la educación actúa con intencionalidad pedagógica que es el conjunto de conductas implicadas con fundamento de elección técnica en la consecución de la meta educativa. Su acción opera como determinante externo de la conducta del agente educando, es decir, de lo que éste va a hacer para que se produzca en él el resultado educativo. Pero como en el educando el estímulo externo (lo que el educador dice que, con fundamento de elección técnica, debe hacerse), es transformado, si no se le anula su condición de agente, en un evento mental sin consecuencias ejecutivas necesarias, hay que tener en cuenta el posible desarrollo de los determinantes internos de la conducta del educando (Touriñán, 1991, 2005a).

El educando es agente de los cambios educativos que en sí mismo se producen, porque "por alguna razón" los quiere, si bien su intención no tiene por qué ser la de educarse en cada caso. Como dice Pinillos:

La forma en que inicialmente se libera el hombre de la tiranía del estímulo es la conversión de éste en un evento mental sin consecuencias ejecutivas necesarias [...]. Esa representación mental puede reanudar la causación interrumpida transitoriamente y dirigir la actividad cerebral hacia una respuesta efectiva quizás adaptativa, pero no directamente determinada por la estimulación (Pinillos, 1978, 29).

Respetar la condición de agente en el educando exige, a fin de no incurrir en coacción, que los cambios educativos se propongan en una situación querida o aceptada por el educando. Y en este caso, si el educador no es manifiestamente incompetente en su función, no ocurre nada antipedagógico por reconocer que, en un cambio educativo específico, no se es capaz de conseguir pedagógicamente que el alumno se determine hacia la conducta que le propone. Existe un límite a la capacidad pedagógica del educador y existe un límite en la capacidad de los educandos de interesarse por cualquier cambio educativo (Touriñán, 1981; García Carrasco y García del Dujo, 1996).

En definitiva, en la intervención pedagógica, de lo que se trata es de generar hechos y decisiones pedagógicas. La condición de experto viene dada por estar en posesión de competencias desarrolladas con el conocimiento teórico, tecnológico y 
práctico de la educación, el dominio de la complejidad estructural de la toma de decisiones pedagógicas y el entrenamiento en la intervención como especialista de la educación (Touriñán, 1995).

Desde la condición de experto, cabe la posibilidad de hablar de profesionales de la educación y de profesiones pedagógicas. Esto, evidentemente, no debe contradecir el hecho, ya apuntado, de que no toda persona que educa es un profesional de la educación, porque los profesionales de la educación ocupan un espacio laboral definido, compatible con la actuación de otros profesionales del sistema educativo y con la de otros agentes de la educación. Pero es precisamente el conocimiento especializado de la educación el que otorga la competencia de experto al profesional de las funciones pedagógicas.

No se trata de abordar aquí el problema de qué conocimiento de la educación se necesita en la intervención pedagógica; ello requiere un espacio específico, pero es obvio que según el tipo de problemas que estemos planteando, unas veces necesitaremos ciencia de la educación (para reglas y normas derivadas del proceso), otras veces necesitaremos estudios científicos de la educación, teorías prácticas y teorías interpretativas (reglas para fines dados y orientaciones de la acción hacia determinados efectos que justifica la teoría interpretativa); y también necesitaremos estudios filosóficos de la educación, cuando queramos hacer fenomenología de un fin en sí, estudiar la lógica interna del fin dentro del sistema conceptual de Educación o conocer las consecuencias que se derivan para la educación de una determinada concepción de vida (Touriñán, 1987a).

De todo conocimiento de la educación se deriva un cierto conocimiento pedagógico, porque el conocimiento pedagógico nace del estudio de la intervención, es decir, del estudio de la relación teoría-práctica; y, según el modo de entender el conocimiento de la educación, se genera un conocimiento distinto de la intervención -en unos casos el conocimiento es experiencial, en otros es de teoría práctica y en otros de tecnología específica- (Touriñán y Rodríguez, 1993).

El conocimiento de la educación tiene su manifestación más genuina en el conocimiento pedagógico, que es el que determina la acción profesional en cada función pedagógica. El conocimiento pedagógico nace del estudio de la intervención, y dado que de todo conocimiento de la educación se deriva a través de la relación teoría-práctica una cierta consideración o recomendación para la intervención, puede decirse que de todo conocimiento de la educación se deriva un cierto conocimiento pedagógico. Por la misma razón se puede decir que toda intervención educativa es, en cierta medida, una intervención pedagógica, porque en toda intervención educativa hay un componente de conocimiento pedagógico, que nace del estudio de la relación teoría-práctica y que no tiene siempre el mismo nivel de elaboración técnica en su manifestación. Y si esto es así, se sigue que en un determinado tipo de intervención educativa hay un conocimiento pedagógico experiencial, en otro, hay conocimiento pedagógico de 
teoría práctica y, en otro, hay conocimiento pedagógico de tecnología específica (Touriñán y Sáez, 2006).

El postulado básico es que del conocimiento de la educación que se tenga dependerá lo que se va a entender por respuesta eficaz y eficiente en la función pedagógica, porque (Touriñán, 1987b):

- La preocupación pedagógica ha existido siempre, aunque no fuese científica, y la ocupación pedagógica también ha existido siempre, aunque no fuese profesionalizada; pero lo que no ha existido siempre es la misma consideración para la función pedagógica, porque el conocimiento de la educación no ha tenido siempre la misma significación, entendida ésta como capacidad que tiene ese conocimiento de resolver problemas de la educación.

- Toda función se ejerce sobre un determinado ámbito y requiere conocimiento del ámbito. Pero en tanto que ámbito y conocimiento del ámbito son distintos, puede decirse que la estimación social del ámbito en que revierte beneficios la Pedagogía - la educación- no implica necesariamente una estimación equivalente para el conocimiento pedagógico, pues su capacidad de resolución de problemas no despierta la misma credibilidad y confianza que la educación.

\subsection{La familia nos educa}

Se sigue de lo expuesto en el epígrafe anterior que el conocimiento especializado es condición necesaria en la función pedagógica, pero también se sigue que hay educación en la que no intervienen especialistas. Es innegable que los padres educan y que, además, en determinadas ocasiones, los padres son al mismo tiempo padres y profesionales de la educación. Es innegable, por otra parte, que hay procesos de educación informal, que hay autoeducación, e incluso, como dicen algunos, educación espontánea. Ahora bien, que el conocimiento especializado sea necesario para la función pedagógica no significa que cualquier tipo de intervención educativa requiera el mismo nivel de competencia técnica (Touriñán, 1996).

Un padre de familia, no experto en Pedagogía, sabe que, obrando de un modo especial -que ha visto, o que han utilizado con él-, se consigue un cierto efecto educativo. Pero el conocimiento de las razones por las cuales obrando de ese modo se consigue ese efecto es una competencia teórica que requiere estudio especializado. Sólo en la medida que dominamos esa competencia, estamos en condiciones de controlar el proceso y mejorar la intervención.

La función pedagógica requiere conocimiento especializado, pero la realización de una acción educativa no exige más nivel especializado de competencia técnica que el requerido para hacer efectiva la meta propuesta. Y esto quiere decir que existen muy diversas intervenciones que no pueden ser resueltas sin alto nivel 
de competencia técnica y que existen otras intervenciones cuya generalización y repetición las convierten en conocimientos especializados de uso común.

Cabe afirmar, en principio, que, si bien no con el grado de elaboración que tiene en las acciones de los profesionales de la educación, el conocimiento especializado está presente en los procesos de intervención educativa, personal y familiar, sean éstos no formales o informales. Y precisamente porque las áreas de intervención educativa familiar tienen su propia complejidad, tiene sentido hablar de educación de padres, de educación familiar y de formación de especialistas (Touriñán, 2001).

La familia, por decirlo en el sentido más clásico de la Pedagogía, constituye el primer conjunto de estímulos educativos para la persona humana; la familia es la paidocenosis fundamental. Las paidocenosis son conjuntos de estímulos vinculados, tan estrechamente, que llegan a formar un todo determinante de un particular tipo de educación (García Hoz, 1970, 245). En términos de esquema conceptual, la educación familiar permite distinguir elementos personales, materiales y formales (las relaciones) y actúa fundamentalmente sobre diversos aspectos cualitativos de la propia vida y educación, que configuran las áreas específicas de la educación familiar (el cultivo de la personalidad, la formación predominantemente moral y religiosa y la adaptación y orientación de la forma de vida personal) (Aznar, 1998; Pérez Serrano, 1998; Fuenmayor, 1998; Ortega y Mínguez, 2003; Pérez Alonso, 2007a).

Resulta de especial interés enfatizar que, en el ámbito de la educación familiar, la imputabilidad absoluta de las acciones y la responsabilidad compartida de las consecuencias establecen un carácter peculiar distintivo respecto de lo que es propio de la sociedad competitiva. En la vida familiar cualquier hecho puede ser imputado normalmente a quien lo ha ejecutado, pero también es verdad que la familia (padres y hermanos), en la mayor parte de las ocasiones, no tiene ningún inconveniente en conformarse con imputar a cada miembro su acción, sin tener interés en que sufra individualmente las consecuencias de ella; el perdón, el sentimiento, la afectividad y la empatía forman parte del normal modo de crecimiento y maduración en el ámbito familiar.

La relación directa es el típico modo de influencia familiar. En el ambiente familiar se encuentran los primeros estímulos para el desarrollo intelectual, moral y social. Las relaciones objetales, el lenguaje, las nociones primeras y básicas de número y espacio, las normas de conducta social de cooperación o de agresividad, de dominio o de sumisión, de relación o de segregación, de generosidad o de egoísmo son consecuencia de los principios operantes en la vida cotidiana familiar, aunque también, en buena medida, pueden ser objeto sistemático de enseñanza (Sarramona, 1998).

Como paidocenosis, a través de la educación familiar, se matiza la vida personal de los sujetos en cuestiones tan fundamentales como el gusto estético y el tono vital; el predominio de la alegría o de la tristeza, del optimismo o del pesimismo; son vivencias y adquisiciones a las que se llega, más que por medio de la 
enseñanza, por su vivencia constante dentro del ambiente familiar adecuado. En todo caso, la acción educativa de la familia no se reduce simplemente a la vivencia diaria, sino que también se identifica con la relación, voluntariamente educativa, de los padres y los hijos con objeto de crear y mantener un adecuado ambiente familiar.

Nada más trivial a primera vista, pero acaso nada más profundo, que afirmar que el hombre nace, crece, se hace en y con la familia; entra en la sociedad a través del subgrupo cultural, económico e ideológico de la familia. Carecer de condiciones familiares no es para el ser humano algo así como encontrarse desheredado de los bienes adicionales de la fortuna, sino de manera radical, encontrarse privado de la urdimbre constitutiva de su ser. Desde el punto de vista positivo, la familia, con su herencia biológica y su ambiente íntimo, forma el ser del niño que se hará adulto. Precisamente por eso, frivolizar sobre el sentido de la familia como unidad social en sus posibles manifestaciones culturales es ignorar las leyes básicas de la existencia humana en la historia de la convivencia de los hombres.

Es de justicia en este apartado recuperar las palabras de Rof Carballo en el libro La familia, diálogo recuperable, cuyo pensamiento central me atrevería a resumir del siguiente modo:

Las tensiones de la vida moderna son mala preparación para el diálogo materno y la vida laboral de la mujer no ha sido hasta ahora suficientemente protegida en lo que al diálogo más importante para el hombre concierne, por falta de sensibilidad para estas cuestiones en los gobernantes y legisladores. Y ipor qué no decirlo también?, por una colosal y hasta criminosa ignorancia en los que sobre estas cuestiones les asesoran. [...] El mal ha de ser atajado en su raíz. Uno de los elementos imprescindibles es afrontar con denuedo los estudios sobre estos temas, las investigaciones y las divulgaciones. [...] La disminución de la tutela diatrófica, el raquitismo de la ternura, la asfixia del diálogo constitutivo lanzará al mundo, en proporción creciente, millones de seres en apariencia inteligentes, cultivados, diestros en admirables raciocinios. Pero profundamente tarados en su núcleo espiritual, pre-esquizofrénicos o pre-psicóticos, delincuentes potenciales o neuróticos graves, o liminares, como se dice ahora (Rof Carballo, 1976, 397).

Estas palabras del profesor Rof Carballo, dichas hace más de 30 años, tienen el valor de la predicción y la autoridad del experto que anticipaba como consecuencia de la merma del interés por la educación familiar la aparición de perjuicios sociales muy graves que han sido estudiados desde el punto de vista jurídico, laboral, psicológico y socioeconómico por muy diversas personas en las tres últimas décadas.

En términos clásicos del papel de la familia en el desarrollo, hay una urdimbre afectiva que, desde la vida de familia, repercute en nuestro desarrollo y hay un diálogo recuperable en la vida de familia que requiere nuevas respuestas y nuevas formas de actuación para desarrollar nuestras destrezas de educación familiar, 
porque la urgencia e importancia de su influencia condiciona nuestra vida futura (García Carrasco, 2007).

La educación es factor de desarrollo social y la familia es factor de desarrollo educativo; ahora bien, la modernización social ha promovido modificaciones en cuanto a las características básicas de la socialización primaria que tiene lugar en la familia. La modernización social ha promovido, entre otros fenómenos, la incorporación de la mujer al mercado de trabajo, la tendencia a reducir el número de hijos, el aumento de las separaciones y del número de hijos que viven solos o con uno de sus padres, la diversidad de configuración de la estructura familiar, etcétera. Aun cuando no es posible generalizar a todas las culturas la existencia de estos fenómenos, resulta interesante mostrar el caso extremo de Estados Unidos, donde, si las tendencias actuales se mantienen, menos de la mitad de los niños y niñas nacidos hoy vivirán con su propia madre o padre durante su niñez, y un número creciente de niños y niñas experimentarán la ruptura familiar dos o tres veces durante ese periodo (SITE, 2004; Benso y Pereira, 2007).

Con la modernización social se produce una disminución significativa del tiempo real que los adultos pasan con sus hijos, y ese tiempo es ocupado ahora por otras instituciones como las guarderías, los clubs sociales o por la exposición a los medios de comunicación, en especial la televisión y las redes; pero lo más significativo es que, con la reducción de ese tiempo, también se limitan las oportunidades de realizar la acción educativa familiar que consiste en insistir en y con los mismos estímulos y normas reiteradamente (Meil, 2006).

En nuestros días, se ha modificado radicalmente el sentido de la socialización familiar tradicional puesto que actualmente todos -sepan o no leer- tienen acceso a la información a través de los medios que no discriminan momentos ni secuencias en la difusión de la información. Los niños llegan a la escuela y desarrollan su escolaridad sin el apoyo familiar tradicional. En un sentido profundo se ha producido una nueva disociación entre la familia y la escuela, porque al modificarse el sentido básico de la socialización primaria los niños llegan a la escuela con un núcleo de desarrollo de la personalidad caracterizado, bien por la debilidad de los marcos de referencia (falta de tiempo y capacidad para generar modelos en la vida familiar), bien por marcos de referencia que difieren de los de la escuela (Elzo, 2003; González, 2006; Pérez Alonso, 2007b; Torío, Peña y Rodríguez, 2008).

En nuestros días, a la familia se le exige suplir con eficacia y calidad la merma de oportunidades de compartir el tiempo con los hijos. Pero, por otra parte, tampoco debemos olvidar que la escuela sigue manteniendo una estructura tradicional, mientras que la familia se ha modificado muy significativamente en los últimos treinta años y esa diferencia incrementa la patente evidencia de la oportunidad y necesidad de reforzar la educación en su sentido axiológico (Consejo Escolar del Estado, 2001). 


\subsection{La sociedad civil es agente moral}

La sociedad civil es agente moral, porque la sociedad civil actual tiene un papel de singular importancia en la promoción y fomento de la vida ciudadana. El término "sociedad civil" ha sido objeto de muy diversos estudios y es mi opinión que su uso licencioso ha generado ambigüedad contextual y semántica (Salamon, 2001; Pérez Díaz, 1993, 1996, 1997). Hoy hablamos de "sociedad civil socialista" y de "sociedad civil liberal", con la misma convicción que hablamos de "sociedad civil internacionalista". Ahora bien, en el contexto de la mundialización, tiene sentido hablar de "sociedad civil global", "sociedad civil transnacional" y "sociedad civil mundializada". Conviene insistir en que el significado de "sociedad civil" es un asunto complejo ya que tal expresión no se refiere sólo a las instituciones, asociaciones, grupos o individuos en cuanto tienen intereses y actividades complementarias o contrapuestas a las de las instituciones del Estado.

La sociedad civil se entiende de muchas maneras. Nos parece muy sugerente la tesis que la concibe como un espacio público de acción social distinto del Estado y del Mercado (Walzer, 1993; Guiddens, 1999; Barber, 2000). La sociedad civil, así entendida, comparte con el gobierno el sentido de lo público y un respeto por el bien general, si bien, al contrario que el gobierno, no reclama el monopolio de legítima coacción. La sociedad civil comparte con los mercados la idea de la libertad como una cualidad fundamental en las relaciones humanas y en las iniciativas de las instituciones pero, a pesar de ello, no es individualista sino que busca el bienestar público.

Tal concepción tiene el atractivo de reivindicar para la sociedad civil un lugar de encuentro para la acción social entre y fuera de dos sectores muy poderosos, el Estado y los mercados que, con frecuencia, dejan indefensos a los ciudadanos. Cuando el gobierno se apropia de "lo público" en exclusividad, el auténtico público, el "tú" y el "yo", deja de pensar de sí mismo como un "nosotros", y los políticos y los burócratas se consideran los únicos representantes de los intereses generales. Los mercados controlan con mano de hierro la vida de las gentes y de las instituciones sociales buscando el beneficio y la rentabilidad económica de los grandes emporios financieros y empresariales, a veces con el empobrecimiento de sectores de población y de países enteros (Touriñán, 2003).

La concepción de sociedad civil, que defendemos, reclama el carácter público de su ámbito puesto que, aunque sus instituciones o asociaciones se constituyen por la libre decisión de sus miembros y sus actividades se realizan de forma voluntaria como grupos asociados libres, esas asociaciones se diferencian del sector privado en la búsqueda de un bien común; sus actividades son voluntarias y, sin embargo, no están privatizadas.

No creemos que haya que confundir lo público con lo estatal (Arendt, 1974). La sociedad civil está formada por asociaciones de ciudadanos que deliberan en común y generan proyectos de acciones en común para solucionar problemas comunes o alcanzar metas compartidas de desarrollo; en ese sentido, su ámbito de 
actuación es público. También las instituciones de la sociedad civil asumen compromisos de actuación social cuando el gobierno no lo hace o no puede hacerlo o se puede hacer mejor desde tales asociaciones. Las instituciones de la sociedad civil pretenden, como objetivo fundamental, el fomento del autogobierno de los ciudadanos. Por ello, lo que tendrían que hacer los gobiernos, que quieran mantener sociedades vigorosas, es limitar y descentralizar su poder promoviendo una sociedad civil activa.

Sin embargo, la sociedad civil no debe sustituir las funciones del gobierno, ni el compromiso o la responsabilidad de cada individuo consigo mismo y con los demás. Respecto al primer asunto, es conveniente distinguir entre la descentralización del poder y la privatización del mismo en manos de una entidad privada. Cuando el gobierno delega o comparte su poder con las instituciones de la sociedad civil potencia la labor de esas instituciones en los escenarios en los que ejercen sus actividades y estimula la responsabilidad de los ciudadanos. Cuando el gobierno abandona sus responsabilidades y privatiza el poder, deposita su confianza en las fuerzas del mercado, que se caracterizan por tener como objetivo la ganancia o interés propio, y abandona la responsabilidad por los intereses públicos. Los gobiernos que descentralizan su poder estimulan la participación de las asociaciones de la sociedad civil, sin abdicar del poder y la responsabilidad por los asuntos generales para los que han sido elegidos; los gobiernos que privatizan el poder, en asuntos de bienestar público, con frecuencia abdican de sus responsabilidades políticas y sociales.

La idea que defendemos de sociedad civil es normativa, se refiere a cómo la sociedad civil "debería ser", si queremos sociedades profundamente democráticas. Tal como la entendemos, la sociedad civil puede establecer los límites sobre el gobierno sin ceder los bienes públicos a la esfera privada y, al mismo tiempo, controlar el deseo de ganancia, a veces inhumano, que circunda a los mercados, sin ahogarse en los vapores de un grande y todopoderoso gobierno.

¿Quiénes conformarían ese espacio intermedio o sociedad civil? Todo tipo de asociaciones constituidas por personas que deliberan en común sobre sus problemas e intereses para también actuar en común tratando de responder a los mismos. Estas asociaciones, para conformar la sociedad civil, tienen que reunir determinadas condiciones: estar abiertas a la incorporación de nuevos miembros que compartan los mismos problemas e inquietudes y que estén dispuestos a colaborar en los fines de la asociación; ser inclusivas y que no nieguen a los ciudadanos la posibilidad de pertenencia por razón de religión, etnia, género o situación económica; y, como tercera condición, deben hacer valer cierto grado de igualdad entre sus miembros.

Para nosotros, sociedad civil y ciudadanía son términos asociados y afines, en cuanto se refieren a individuos e instituciones cuyos derechos o deberes están garantizados o exigidos por las leyes de un Estado, o deberían estarlo. Precisamente por eso, conviene no olvidar que, en cualquier caso, cuando hablamos de construir desarrollo cívico, estamos enfatizando la importancia de la participación 
y la responsabilidad de todos en el desarrollo de competencias para los asuntos sociales en un marco legal territorializado que implica a diversas y plurales organizaciones (Ortega, 2004a; Escámez y Gil, 2002; Touriñán, 2002, 2004).

Como decíamos al principio de este trabajo, la condición de ciudadanía y la convivencia pacífica permiten a los humanos hacer valer su humanidad, porque una sociedad civil es deseable, si sus miembros promueven y gestionan valores y propician líneas de cooperación entre las personas. Es por eso que la sociedad civil, el desarrollo, la interculturalidad, la ciudadanía, el trabajo, la identidad y los derechos de la persona humana son cuestiones actuales impregnadas de valores y su aprendizaje y la manera de asumirlos y comprometerse, personal y constitucionalmente, con ellos marca el contenido de la educación en su sentido axiológico, que es el sentido más profundo de la educación; es decir, la educación en cuanto cuestión axiológica (Ortega y Mínguez, 2001; Escámez, 2003).

Lo social, si no se tergiversa su sentido, hace referencia a aquellas situaciones de relación entre las personas, a aquellas situaciones de reciprocidad en las cuales se pretende que cada hombre pueda alcanzar de modo más completo su bien privado con unos medios que no le pertenecen exclusivamente. En estas situaciones, todos tenemos que ordenar intencionalmente nuestras disposiciones para cumplir los derechos y obligaciones que nos atañen a fin de que lo social se realice correctamente (Touriñán, 1979).

Entendemos que en esta propuesta la Familia, la Escuela, el Estado y la Sociedad Civil son agentes que integran y desarrollan la educación y entendemos, además, que, ahora, la Sociedad Civil puede reforzar a la Familia y a la Escuela de un modo singular y distinto al del Estado para fortalecer el papel de los padres en la educación de los hijos (Touriñán, 2004, 2003; Naval, 2002).

Reiteramos, por tanto, que, en nuestros días, el sentido de lo social se ha enriquecido, debido al carácter transnacional de las acciones globales. Ya no hablamos simplemente de derechos sociales que requieren la subsidiación del Estado con unos medios que no pertenecen a ningún individuo en particular; hablamos de derechos que reclaman la cooperación positiva de los estados y la sociedad civil, más allá de las fronteras territoriales. Esto modifica el carácter de territorialidad del Estado y el sentido del compromiso de la sociedad civil.

Como todos sabemos, la educación tiene reservado un papel fundamental en el desarrollo personal del individuo, al igual que lo tiene en el desarrollo de las sociedades. Es decir, socializa y forma al ciudadano para su incorporación más o menos mediata a la comunidad a la que pertenece, hecho en el cual resulta fácilmente observable la importancia de la necesaria implicación de todos con miras a alcanzar la sociedad deseable. Son unas nuevas reglas de juego en las que Estado, Sociedad Civil y Mercado son corresponsables del desarrollo mundial (Touriñán, 2006a).

Hoy se denuncia la falta de un modelo social más humano que requiere de la implicación de toda la sociedad. El sistema educativo actual genera responsabilidades a todos los niveles, no sólo para los profesores y alumnos, sino 
para los padres, la comunidad y la sociedad civil. Todos somos responsables de la educación que reciben nuestros niños, por lo que también estamos directamente relacionados con el futuro de esas generaciones, es decir, con el tipo de sociedad que conformen.

En consecuencia, es un objetivo básico de la Pedagogía hacer comprender que la educación, entendida en su sentido pleno, no alcanza su objetivo con desarrollar un hombre capaz de valerse por sí mismo y para sí mismo. Además, debe entenderse que este núcleo personal no estará conseguido mientras que la educación no salvaguarde y cultive en cada educando el sentido de la relación con el otro, es decir, el sentido social de la diversidad y la identidad en los espacios de convivencia, lo cual implica llegar a asumir el compromiso con los principales derechos y obligaciones que como ciudadanos y como miembros de la comunidad deben cumplirse en el marco legal territorializado.

La responsabilidad es un hecho y una cuestión de derecho que implica la existencia y convivencia de valores y de modos de vida diversos; pero además es un ejercicio de voluntades y un compromiso moral, porque los conocimientos de por sí no mejoran necesariamente la comprensión del otro, ni la relación (Touriñán, 2006a).

Se trata de entender que se ha modificado de tal manera el marco del desarrollo humano que el reto es hacer frente a la responsabilidad compartida corporativamente, sin renunciar a las competencias de cada una de las instituciones implicadas. Ni los padres son los profesionales de la educación, ni la escuela tiene que suplantar o sustituir la función de la familia. Ni el educando debe dejar de ser agente de su educación. Sociedad civil, familia, Estado y escuela afrontan el reto de la formación, no sólo como una cuestión de hecho, sino como un compromiso de voluntades hacia lo que es valioso en la educación: el desarrollo personal y la convivencia pacífica en la sociedad abierta y pluralista. De tal manera, que la solución en la educación no está en elegir en lugar del educando su modo de vida, sino en elegir aquellos modos de intervención pedagógica que garantizan la capacitación del educando para elegir, aprendiendo a construir y usar experiencia para responder a las exigencias en cada situación, de acuerdo con las oportunidades (Touriñán, 2004, 2006b).

Se sigue de lo anterior que la educación debe ser contemplada y, por ello, aprovechada como una experiencia de participación y de aportación personales al conjunto de la sociedad. Los cauces de participación y de acción ciudadana, desde el punto de vista de la intervención pedagógica y la legitimación de medidas exigen que se genere una responsabilidad social y jurídica compartida hacia el uso y la construcción de experiencia axiológica respecto de la convivencia pacífica y los valores derivados de los derechos humanos en el marco constitucional que garantiza derechos y libertades. Y esto que acabamos de decir contribuye a resaltar el papel de la sociedad civil como agente moral. 


\subsection{La educación es una tarea de carácter axiológico y patrimonial}

La educación se perfila cada vez más como proceso de maduración y aprendizaje que implica el desarrollo de la inteligencia, la voluntad y la afectividad, orientado al uso y construcción de experiencia axiológica para decidir y realizar un proyecto personal de vida, dando respuesta de acuerdo con las oportunidades a las exigencias que se plantean en cada situación; es un proceso, en definitiva, con sentido integral, personal y patrimonial en un entorno social, cultural y personal diverso (Touriñán, 2005b, 2006b).

En este contexto la escuela, la familia y la sociedad civil tienen que propiciar por ellas mismas la posibilidad de preparar a los individuos para la innovación. La función educadora requiere la utilización del pensamiento y de la experiencia personal enriquecida por la propia comunidad humana. Esto es así porque se favorece una actividad socialmente organizada, en un marco de relaciones inter e intra personales que ayudan a la construcción individual de cada sujeto.

Inteligencia, voluntad y afectividad se organizan a través de la educación en procesos orientados desde esas tres dimensiones generales a desarrollar personas, que son sujetos de derechos de primera, segunda y tercera generación en los que se contempla ya de manera inequívoca la diversidad y la inclusión como formas genuinas de esos derechos.

Espacio, tiempo y persona son ejes-fundamento de la Intervención Pedagógica. La educación tiene que estar a la altura de los tiempos y propiciar el tránsito desde determinantes externos de conducta a determinantes internos con sentido personal y patrimonial en el resultado de la educación, realizando una intervención de calidad, desde las tres dimensiones generales de intervención, en todas las áreas del currículum.

El currículo escolar de la educación tiene que dar respuesta a los ámbitos de educación general que configuran al humano actual, proporcionando respuestas de contenido propio de las áreas de expresión (plástica, dinámica, matemática, lingüística) y experiencia (histórico-social, natural, trascendental, geográfico-ambiental, audio-visual-virtual), atendiendo al carácter axiológico de la educación que impregna la intervención, las finalidades y la selección y organización de contenidos de la educación.

El reconocimiento de la importancia de la afectividad y de la relación con el otro en nuestra educación es acorde con la condición de agentes de nuestro propio desarrollo que nos aboca necesariamente a la defensa de la educación integral y personal con sentido patrimonial (Ortega, 2005; Pérez Juste, 2005; Touriñán, 2005b, 2006b). La educación integral quiere decir formación intelectual, afectiva y volitiva, para ser capaz de afrontar con libertad y posibilidades de éxito las situaciones que se nos plantean en todos los ámbitos de la vida: personal, familiar, social, profesional, etc. La educación personal quiere decir que se ayuda al educando a inventar o crear modos "originales-singulares" de realización de la existencia con autonomía y responsabilidad, dentro del espacio participado de una cultura, apartándose de 
la repetición o clonación de modelos preestablecidos. La educación patrimonial quiere decir que intervenimos pedagógicamente y trabajamos del mismo modo para que el educando aprenda a hacer uso patrimonial de la formación, de tal manera que lo aprendido pase a formar parte de su experiencia personal y construya con ella su proyecto de vida y su formación (Touriñán, 2006b).

De las reflexiones anteriores se sigue que, además de estimar personalmente el valor, tenemos que elegirlo, como parte integrante de nuestras finalidades. No por otra cosa, sino por ésta, se puede decir que la educación adquiere, además de sentido personal e integral, carácter patrimonial, porque, cuando nos marcamos finalidades, no sólo hacemos una estimación del valor, sino que también asumimos ese valor en la finalidad como una parte integrante de nuestro proyecto de vida; hacemos, de nosotros, nuestro propio patrimonio.

Afirmar el carácter patrimonial de la educación no quiere decir simplemente que existe un patrimonio cultural externo que hay que cuidar y que forma parte del acervo educativo. Nosotros reclamamos para "patrimonial" un significado intrínsecamente anclado en el concepto de educación como desarrollo y construcción de la persona de manera integral. Afirmar el carácter patrimonial de la educación quiere decir que somos, cada uno de nosotros mismos, un patrimonio; que aprendemos a elegir, a decidir y a marcarnos finalidades, para poder determinar nuestro proyecto de vida, dando respuesta a nuestras necesidades en cada circunstancia, construyéndonos a nosotros mismos como nuestro patrimonio más propio. Decidir cuál de nuestras necesidades debe ser atendida, aquí y ahora, en nuestro proyecto de vida, supone deliberar y asumir, atendiendo a los conocimientos, valores, sentimientos, actitudes e intereses que tenemos en ese momento; un patrimonio que nosotros podremos corregir y variar amparados en las oportunidades, en las circunstancias y en la educación recibida, pero que no podemos evitar tener en el momento de adoptar la decisión (Touriñán, 2006b).

Si estas reflexiones son correctas, se puede concluir, respecto del sentido axiológico de la educación en valores, que la educación en valores sigue siendo una necesidad inexorable: tenemos que orientarnos y aprender a elegir, hay que estar capacitado para optar, porque nuestro proyecto de vida, individual y socialmente, es, de hecho, una cuestión abierta y, de derecho, un compromiso de voluntades, axiológicamente orientado hacia un mundo personal y social mejor.

La educación es, por tanto, un valor y, además, desarrolla valores. El sentido axiológico y su permanencia en la educación nos llevan a defender que la educación desempeña un papel decisivo en el desarrollo (Delors, 1996; Hallak, 2003; Ortega, 2004b; Touriñãn, 2008b; Morin, 2000; Savater, 2000; Ibáñez-Martín, 1975; Vázquez Gómez, 2001):

- La educación es elemento fundamental para el éxito de la integración en un mundo que reclama competencias específicas para "aprender a ser", "aprender a hacer", "aprender a aprender" $\mathrm{y}$ "aprender a vivir juntos". 
- La educación es uno de los instrumentos más eficaces para promover y proteger la identidad cultural.

- La educación es la vía adecuada para conseguir personas autónomas capaces de defender y promover los derechos en un mundo globalizado.

La educación carece de toda justificación inteligible, cuando se rechaza el carácter fundamentante de los valores: si el hombre no tiene una inserción preestablecida en una forma concreta de hacerse -hecho incontrovertible, porque no todos tenemos que ser lo mismo en la vida necesariamente- se infiere que sólo decidirá realizarse de un modo concreto cuando le sea posible desvelar el valor de esa forma específica de llevarse a cabo, con su capacidad y con la ayuda de los demás (Touriñán, 1977a; Nassif, 1980; Mantovani, 1972a, 1972b; Marín Ibáñez, 1976, 1983; Gervilla, 2000).

Pero, además, como el hombre no nace perfecto, ni alcanza la perfección que le es propia de modo espontáneo, se sigue que no entenderá correctamente el valor de tal forma concreta de realizarse, mientras que la educación no ponga los medios adecuados para que él pueda forjarse una capacidad de elección lúcida (Varios, 1983; Castillejo, 1994; Touriñán, 1989; Puig Rovira, 2003).

En consecuencia, desde el punto de vista de la lógica, los valores son fundamento de la educación y puede decirse que es falsa toda proposición que pretenda negar la necesidad de presuponer un modelo de persona al cual se orienta y en el cual se realiza cada persona, si lo aprehende y estima como deseable y posible. Y es esta relación entre educación y valores la que hace de la educación en valores una necesidad inexorable (Touriñán, 2005c; Castillejo, 1994).

Puede decirse, por tanto, que el sentido axiológico de la educación nos aboca necesariamente a la defensa de la educación integral y personal con sentido patrimonial, porque de lo que se trata en educación en valores es de aprender a construir y a utilizar la experiencia axiológica para desarrollar nuestro proyecto personal de vida y formación.

Desde el punto de vista de la realización del valor, tan importante es en la educación en valores, el conocimiento y la estimación personal del valor, como el carácter patrimonial de la elección del valor, porque, en ambos casos, se pone de manifiesto nuestra condición de agentes de nuestra educación y de nuestro proyecto de vida.

La relación entre elección y realización de valores a través de las finalidades que nos marcamos nos pone en la vía de resaltar el carácter patrimonial de la elección del valor que impregna el sentido de la educación y que es a donde se tiene que llegar con la investigación pedagógica, cuando enseñamos el valor y ayudamos a conocer, estimar, elegir y realizar el valor en relación con el otro.

Estamos convencidos de que la educación en valores es una necesidad inexorable y es un reto ineludible que debemos abordar desde estrategias de encuentro. Esto es así, porque la tensión entre la defensa de la propia identidad, la comunidad y el imperativo de mundialización fuerza a los individuos 
a enfrentarse a los problemas con sentido axiológico (Touriñán, 2003; Ortega, 2004b).

\section{El DeSARROllo Cívico es una ReSPONSABILIDAD DE FORMACión}

En nuestros días, el choque de civilizaciones (Huntington, 2001; Berger y Huntington, 2002), que es un hecho provocado por fundamentalismos enfrentados, puede ser transformado, mediante un compromiso de voluntades personales e institucionales orientado a la alianza de "civilización" (desarrollo cívico) para vivir juntos y en paz en un mundo mejor en el que la educación es, cada vez más, el instrumento eficaz de transformación y adaptación del hombre como ciudadano del mundo, pero localizado, que es capaz de solucionar conflictos reales sin convertirlos en guerras de religión y/o identitarias (Touriñán, 2004, 2006b). Como dice Morin, se plantea a las sociedades conocidas como democráticas la necesidad de regenerar la democracia (mientras que, en una gran parte del mundo, se plantea aún el problema de generar democracia), al mismo tiempo que las necesidades planetarias nos piden engendrar a su nivel una nueva posibilidad democrática: «la regeneración democrática supone la regeneración del civismo; la regeneración del civismo supone la regeneración de la solidaridad y la responsabilidad" (Morin, 2000, 120).

El desarrollo cívico es un problema de educación en valores y un reto ineludible que debemos abordar desde estrategias de encuentro, profesional y personal. El conflicto y la confrontación pueden canalizarse mediante el compromiso de voluntades personales e institucionales orientado al desarrollo cívico en un proceso en el que la educación es, cada vez más, el instrumento eficaz de transformación y adaptación del hombre como ciudadano del mundo, pero localizado.

La buena educación tiene valor de símbolo y lo que simboliza es la realidad social. La educación para la convivencia ciudadana aparece así como un ejercicio de educación en valores orientado al uso y construcción de experiencia axiológica relativa al desarrollo cívico.

\subsection{En la educación para la convivencia hay que cualificar y especificar}

Atendiendo a estas consideraciones, parece incuestionable que es preciso poner de manifiesto los "límites" pedagógicos del concepto de educación para la convivencia, de manera tal que podamos hablar con sentido en educación de interculturalidad, de crecimiento personal y de respeto al otro, sin reducir la formación a un problema de convivencia, ni atribuir a la formación para la convivencia más extensión de ámbito que la que le corresponde dentro del sentido integral, personal y patrimonial de la educación. Es preciso que la Pedagogía se interrogue sobre esas diferencias y forme en los diversos niveles de convivencia, atendiendo a la 
especificidad de los espacios convivenciales, con objeto de atribuir a la formación para la convivencia el lugar que le corresponde dentro de la educación social y la educación en general.

Y en ese sentido, lo primero que hay que hacer es cualificar la convivencia, porque la clave en la formación para la convivencia es lo que estamos dispuestos a asumir. Como ya sabemos, la existencia y convivencia de valores y de modos de vida diversos hacen de la interculturalidad un hecho y una cuestión de derecho que implica, además, un ejercicio de voluntades y un compromiso moral, porque los conocimientos culturales, de por sí, no mejoran necesariamente la comprensión del otro, ni la relación entre personas (García del Dujo, 2005; Olveira, Rodríguez y Touriñán, 2006). Hay que cualificar la convivencia, porque de no hacerlo, derivamos para la educación estrategias equivocadas, como la que se derivaría de la relación inversa entre convivencia y violencia.

Entender que la convivencia como concepto, y sin ningún tipo de cualificación, mantiene una relación inversa con el concepto de violencia, como si tuvieran las mismas causas pero en sentido inverso, implica atribuir erróneamente a una conexión empírica entre dos conceptos el rango de conexión conceptual. Es cierto que la violencia se produce en los espacios propios de o apropiados para la práctica y el ejercicio de la convivencia; ésa es la evidencia de conexión empírica entre ambos conceptos. Pero no hay, a partir de ahí, conexión conceptual, porque tenemos también la evidencia incontestable de que grupos identificados étnica, ideológica o socialmente, según el caso, manifiestan fuertes lazos y prácticas de convivencia y solidaridad entre ellos y al mismo tiempo se comportan en entornos compartidos con otros miembros o colectivos de manera violenta. Todos tenemos pruebas de este tipo de conexión empírica "convivenciaviolencia" y evidencias de la no conexión conceptual entre ambos conceptos en los comportamientos violentos entre grupos de amigos, entre familias, en sucesos que afectan a grupos fundamentalistas religiosos, étnicos, políticos, pandilleros, etcétera, o entre grupos de "hinchas" en eventos deportivos. En todos estos casos se detecta que hay convivencia dentro del grupo y fuerte solidaridad entre los miembros del mismo, motivada por el sentido de pertenencia al grupo o por las metas que comparten. Hay convivencia pero hay, además, violencia. Efectivamente hay convivencia en el grupo que se manifiesta violentamente y hay fuerte sentido de solidaridad entre los miembros del mismo. Pero esa solidaridad no implica igualdad, ni valor compartido extragrupo. No hay reconocimiento del otro, hay patrón de percepción de que lo otro no cumple las expectativas y se genera un sentimiento negativo que se resuelve en respuesta violenta de diverso nivel y modalidad. La conexión convivencia-violencia es empírica, no conceptual. Se sigue, por tanto, que convivencia y violencia mantienen sólo conexión empírica. Y si esto es así, la convivencia tiene que ser cualificada; la convivencia es, por tanto, la convivencia pacífica.

En esta misma línea de razonamiento nos dice Reboul que la buena educación, ya sea de las maneras, de la mente o del corazón (voluntad, inteligencia y 
afectividad), "tiene valor de símbolo y lo que simboliza es la realidad social; pues la buena educación es de esencia democrática; ser bien educado con alguien es tratarlo como a un igual" (Reboul, 1999, 207). Y en ese mismo sentido, pero desde la perspectiva del valor de la igualdad y la conducta ética frente a la solidaridad como concepto formal, nos dice Gustavo Bueno:

... nada de dibujar la conveniencia de ser solidarios en todo momento. [...] hay que proclamar el valor de la insolidaridad contra la solidaridad sectaria [...] de situaciones en las que la solidaridad envuelve hipocresía, maldad, conculcación de valores irrenunciables, ambigüedad o tolerancia cómplice ante lo intolerable (Bueno, 2006, 206).

Se trata de entender que se ha modificado de tal manera el marco del desarrollo humano que el reto es hacer frente a la responsabilidad compartida corporativamente, sin renunciar a las competencias de cada una de las instituciones implicadas. Ni los padres son los profesionales de la educación, ni la escuela tiene que suplantar o sustituir la función de la familia. Estado, sociedad civil, familia y escuela afrontan el reto de la formación para la convivencia, no sólo como una cuestión de hecho, sino como un compromiso de voluntades hacia lo que es valioso en la educación y debe ser asumido: el desarrollo personal y la convivencia pacífica en la sociedad abierta y pluralista (Touriñán, 2005a).

En el lenguaje común hay una aproximación entre "Convivencia" y "vivir con" que no oculta las diferencias profundas en el uso de ambos términos; unas diferencias que se ponen de manifiesto en la pregunta ¿Con quién vives? Pues, en efecto, yo convivo con mis parientes, con el grupo de amigos, con los miembros del club o asociación, con los ciudadanos, con mis vecinos, etcétera. En cada uno de esos grupos con los que convivo hago unas cosas y no otras. Por eso puedo prestarle una chaqueta a un amigo, pero no se la presto sin más y por desgracia a cualquier compañero de colegio. Pero realmente "vivo con" mis padres o con mi esposa o con mi esposa e hijos, etcétera, según sea el caso. Yo convivo en muchos ámbitos y hay, desde el punto de vista de la educación, espacios, ámbitos o sectores de convivencia y hay, además, niveles de convivencia, pues la convivencia no es la misma en todos ellos, ni se da el mismo nivel de convivencia entre todos los que están en el mismo espacio de convivencia. "Vivir con" no es exactamente lo mismo que "convivir". La Pedagogía se interroga sobre esas diferencias y la escuela forma en un clima de convivencia. Hay que especificar la convivencia. Cada espacio especifica la convivencia, atendiendo a las condiciones propias de ese espacio. En este caso, el espacio escolar es el espacio pedagógicamente programado.

La convivencia se produce en espacios concretos. Ningún contexto de convivencia está libre de amenazas de conflicto y de violencia. Precisamente por eso la educación debe formar para la convivencia y educar para el conflicto. Sin embargo, la carga a favor del problema como problema de voluntades no debe hacernos olvidar que el problema analizado es un problema de legalidad, pero también, 
de manera prioritaria, un problema de legitimidad. La propuesta formativa para la convivencia afecta a cada individuo y la decisión del sujeto aparece, de este modo, como una cuestión de derechos y como una cuestión axiológica y de compromiso ético, que tratamos de reflejar de manera resumida en el siguiente cuadro de elaboración propia (Touriñán, 2007, 276):

Cuadro 1

Educación en valores como uso y construcción de experiencia axiológica

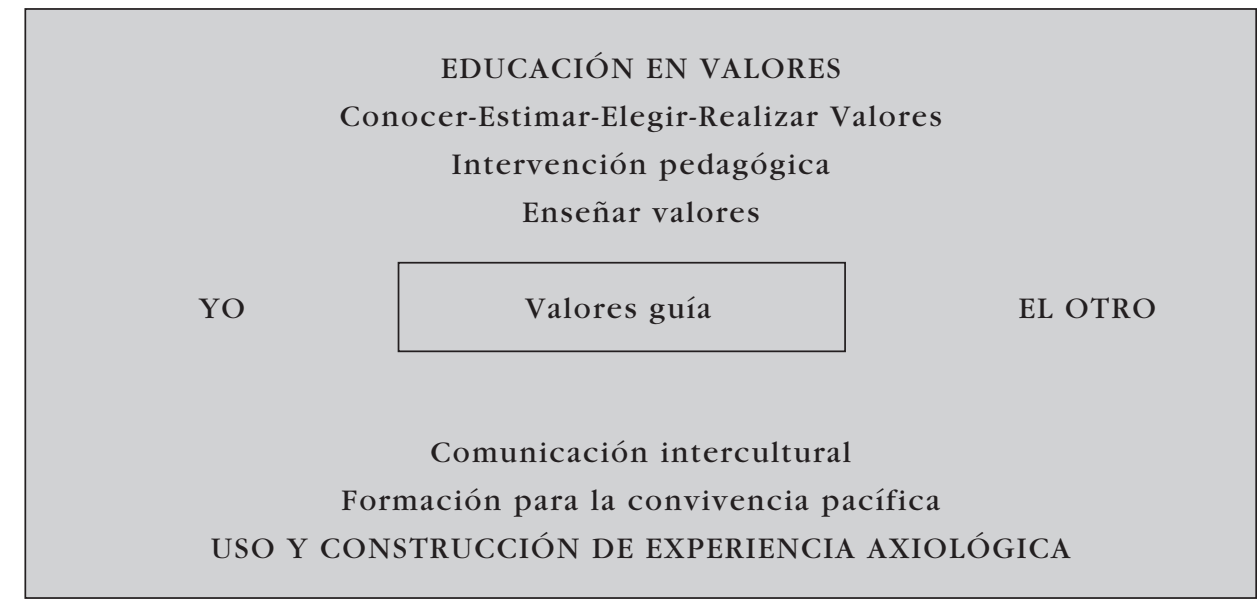

En los espacios convivenciales los valores derivados de los derechos humanos se consolidan como fundamento de la educación para la convivencia pacífica, porque el reconocimiento del otro se funda en un compromiso de voluntades basado en la aceptación del otro, en tanto que persona humana, como ser digno e igual sujeto de derechos en ese entorno y no sólo no hay nada en esos derechos de la persona humana que se oponga al reconocimiento del otro, sino que, además, todo lo que reflejan los derechos de la persona humana contribuye a afianzar el sentido de lo social y tienen que verse como una parte del derecho a y de la educación para no quedar fuera del marco fundamentante de la relación con el otro y de su materialización en el contexto de las libertades reales (Touriñán, 2007).

La propuesta intercultural afecta a cada individuo y la decisión del sujeto aparece, de este modo, como una cuestión de derechos y como una cuestión axiológica y de compromiso ético fundado en la dignidad, la libertad, la igualdad, la identidad, el desarrollo, la autonomía, la responsabilidad, la justicia, la diversidad y la cooperación. Un compromiso ético de voluntades personales e institucionales orientado, como ya hemos dicho, a la alianza de "civilización" (desarrollo cívico) para convivir en un mundo mejor en el que la educación es, cada vez más, el instrumento eficaz de transformación y adaptación del hombre como ciudadano del 
mundo, pero localizado. Precisamente por eso, la comunicación intercultural es un ejercicio de elección de valores; en la comunicación intercultural, necesariamente, tenemos que elegir valores.

El postulado final es que la formación para la convivencia pacífica tiene que realizarse como ejercicio de educación en valores; es un ejercicio de elección de valores, nos lleva al reconocimiento del otro y nos ejercita en el uso y construcción de experiencia axiológica sobre la identidad y la diferencia, para construirse a uno mismo y reconocerse con el otro en un entorno cultural diverso de interacción, que constituye los espacios de convivencia.

\subsection{La convivencia ciudadana es una responsabilidad compartida y derivada de formación}

Hemos de hacer un esfuerzo colectivo orientado a entender que la educación para la convivencia ciudadana, bien como cuestión transversal, bien como cuestión disciplinar, es una cuestión derivada de la educación en valores y dentro del área social de formación para la convivencia. En tanto que propuesta axiológica, la educación para la convivencia está orientada al reconocimiento del otro que se funda en un compromiso de voluntades basado en la aceptación del otro como ser digno e igual sujeto de derechos, en tanto que persona humana en mi entorno. Como decíamos, "Vivir con" no es exactamente lo mismo que "convivir" y convivir pacíficamente no es lo mismo que convivencia ciudadana, porque hay muchos ámbitos de convivencia y diversos niveles de convivencia en cada ámbito (no todo es convivencia pacífica en cada ámbito, ni se da siempre el mismo grado de compromiso con la convivencia en el ámbito) y el espacio convivencial ciudadano se singulariza frente a los demás espacios convivenciales como un espacio de la persona, en tanto que vinculada en su relación con el otro a un territorio legalmente establecido.

Desde el punto de vista de la educación, la Pedagogía debe asumir esas diferencias y matizaciones, tanto desde la perspectiva de los diversos niveles y ámbitos de formación para la convivencia, como desde la perspectiva de integrar en la formación general la formación singularizada del espacio convivencial propio de la ciudadanía.

La formación para la convivencia ciudadana aparece entonces como una responsabilidad compartida y derivada. Compartida, porque todos somos objeto de formación y no todos tienen las mismas atribuciones en el tema. Pero, además, la formación para la convivencia ciudadana es una responsabilidad derivada (de la sociedad como factor de desarrollo educativo y de la educación como factor de desarrollo social), que debe cumplir las exigencias del carácter axiológico de la educación, en lo que corresponde a la formación para la convivencia pacífica en un marco legal territorializado de relación con el otro.

La tesis es que la convivencia ciudadana es una responsabilidad compartida, porque, en primer lugar, en tanto que convivencia, es una convivencia cualificada 
-pacífica- y el logro de la convivencia pacífica es una tarea que no puede delegarse, es inseparable de la participación en los asuntos que afectan a todos los miembros de la misma sociedad y, en segundo lugar, es una responsabilidad derivada, porque, en tanto que ciudadana, es una convivencia especificada, es decir, cumple las condiciones de la convivencia y, además, es relativa a un espacio de convivencia que le es propio - el espacio cívico, ciudadano-, que no es sólo un espacio del individuo formado en su relación con el Estado, sino un espacio de formación e interacción del individuo con y frente al Estado, pero con el otro en un marco legal territorializado de derechos y libertades. Y este sentido de responsabilidad compartida y derivada identifica a la sociedad civil como agente moral y requiere el desarrollo cívico como objetivo.

Se trata de entender que se ha modificado de tal manera el marco del desarrollo humano que el reto es hacer frente a la responsabilidad compartida institucionalmente, sin renunciar a las competencias de cada una de las instituciones implicadas. Estado, sociedad civil, familia y escuela afrontan el reto de la formación para la convivencia ciudadana como un compromiso de voluntades hacia lo que es valioso y debe ser asumido en ese ámbito de formación para el desarrollo personal y la convivencia pacífica en la sociedad abierta y pluralista dentro de un marco legal territorializado.

Nuestro postulado final es que la formación para la convivencia pacífica ciudadana tiene que realizarse como ejercicio de educación en valores; en primer lugar, porque es un ejercicio de elección de valores y, en segundo lugar, porque nos lleva al reconocimiento del otro y nos ejercita en el uso y construcción de experiencia axiológica relativa al reconocimiento de libertades como ejercicio específico de respeto al límite de elasticidad de la tolerancia, en el marco de convivencia del territorio constitucionalmente establecido. Y dado que los valores son cognoscibles y estimables, son enseñables y son elegibles y realizables, la educación en valores y la comunicación intercultural se convierten en referentes de la formación para la convivencia pacífica, con sentido interdisciplinar que afecta de manera compartida a familia, escuela y sociedad civil y coloca a los profesionales de la educación y al Estado en un nuevo reto de arquitectura curricular ante la condición de experto en educación en valores y la real oportunidad de asistir a centros pedagógicamente programados.

En este contexto, se refuerza el sentido de sociedad civil como un agente moral y el del desarrollo ć́vico como objetivo de formación prioritario y de responsabilidad compartida en la educación. La propuesta afecta a cada individuo y la decisión del sujeto aparece, de este modo, como una cuestión de derechos y como una cuestión axiológica y de compromiso ético de voluntades personales e institucionales orientado, como ya sabemos, a la alianza de "civilización" (desarrollo cívico) para convivir en un mundo mejor en el que la educación es, cada vez más, el instrumento eficaz de transformación y adaptación del hombre como ciudadano del mundo, pero localizado. 


\subsection{El desarrollo cívico es objetivo de la formación para la convivencia ciudadana}

Sociedad civil y ciudadanía son términos asociados y afines, en cuanto se refieren a individuos e instituciones cuyos derechos o deberes están garantizados o exigidos por las leyes de un Estado, o deberían estarlo. Precisamente por eso, conviene no olvidar que, en cualquier caso, cuando hablamos de construir desarrollo cívico, estamos enfatizando la importancia de la participación y la responsabilidad de todos en el desarrollo de competencias para los asuntos sociales en un marco legal territorializado que implica a diversas y plurales organizaciones (Salamon, 2001; Ortega, 2004a; Escámez y Gil, 2001; Touriñán, 2004, 2007).

Si esto es así, se sigue que la educación para la ciudadanía no puede separarse, como concepto, del significado que le corresponde al término "desarrollo cívico". El desarrollo cívico tiene un sentido primario -social y comunitario-, que puede quedar oculto en una concepción de la educación para la ciudadanía orientada sólo políticamente a la comprensión y formación del ciudadano en su relación con el Estado y las libertades. La educación para la ciudadanía, que persigue el desarrollo cívico como meta, es indisociable del compromiso ético y sociopolítico con una comunidad concreta; es inseparable de la participación en los asuntos que a todos los miembros de la misma sociedad afectan. No es posible construir un espacio de convivencia territorializado como espacio social de convivencia para todos los ciudadanos en su relación con el Estado en un marco legal de derechos y libertades, sin la participación de todos, pues el uso y construcción de ese espacio exige la convicción y creencia de que los asuntos públicos nos/me atañen, nos/ me afectan, y de ellos también soy/somos responsable/s. Sin la conciencia de que la construcción de la sociedad democrática es una tarea que no puede delegarse, las propuestas de participación ciudadana resultan ineficaces. Sin ciudadanos no hay ciudadanía, es decir, vida democrática y sentido de proyecto común, respecto del marco legal territorializado, que es un espacio de convivencia e interacción culturalmente diverso (Touriñán, Ortega y Escámez, 2006).

Tan importante como la relación del individuo con el Estado, lo es la relación del individuo con el otro, en el marco legal territorializado de derechos y libertades. La educación ciudadana es del individuo con y frente al Estado, pero con el otro, en un marco legal territorializado de derechos y libertades; de ahí que lo que procede es que la educación para la ciudadanía o formación para la convivencia ciudadana no sea reducida a educación política (sobre las relaciones del individuo con el Estado), ni a educación cívica instrumentalizada (estrategia para politizar y hacer política en la educación), sino que se identifique como formación para el desarrollo cívico y una parte sustantiva de la política educativa.

Está fuera de toda duda que el fundamento ético del Estado de derecho y el valor educativo de la legislación justifican la competencia del Estado para proporcionar, en la educación general, formación sobre los valores que legitima y legaliza la Constitución. Pero, además, el carácter de responsabilidad compartida y derivada coloca a la formación para la convivencia pacífica ciudadana, ya sea 
en perspectiva educativa transversal, ya sea en perspectiva educativa disciplinar, en una encrucijada de sentido interdisciplinar que afecta a familia, escuela y sociedad civil y sitúa a los profesionales de la educación y al Estado en un nuevo reto de arquitectura curricular ante la condición de experto en educación en valores y la real oportunidad de asistir a centros pedagógicamente programados.

Desde una determinada perspectiva más individualista puede concebirse la educación para la convivencia ciudadana como una forma de educación política en democracia, orientada a la formación acerca de los derechos y las libertades constitucionales, al dominio de los contenidos de los tratados internacionales ratificados por el Estado y a la comprensión de la organización del poder en el Estado y su estructuración territorial.

Desde una determinada perspectiva más comunitarista puede concebirse la educación para la convivencia ciudadana como la forma propia de la educación cívica en democracia, orientando oportunamente la formación ciudadana a las relaciones del individuo con el Estado y a la difusión y consolidación de los modelos sociales de convivencia legalmente permitidos.

Ambas tendencias, que están vigentes, tienen un desarrollo histórico evolutivo basado en dos de los ejes matriciales de la creatividad cultural: la creatividad cultural científico-tecnológica y la creatividad cultural socio-identitaria (Touriñán, 2002; Kuper, 2001). Estas dos tendencias han consolidado en el tiempo posiciones antagónicas expresadas en distintas épocas bajo alternativas tales como movimiento ilustrado-movimiento romántico, movimientos liberalistas-movimientos societaristas, movimientos globalistas-movimientos ecologistas. En las posiciones comunitaristas se defiende el sentido público respecto de los valores y creencias. En las posiciones más próximas al individualismo se defiende el sentido privado respecto de los valores y creencias. Para los primeros, la convivencia tiene mucho que ver con la idea de compartir identidad y para los segundos, la convivencia se ajusta más a la idea de estar juntos en la diversidad (Lessnoff, 2001; Barbosa, 2008).

Bajo estos antagonismos siempre han estado latiendo la amenaza fundamentalista del adoctrinamiento y la ilusión antipedagógica del neutralismo (Touriñán, 1976, 1977b, 1977c; Gil Cantero, 2008). Frente a esas posiciones, el profesor Ibáñez-Martín ha dado a conocer en el ámbito pedagógico, recientemente, la doctrina europea sobre la legitimidad y legalidad de respetar las convicciones pedagógicas, al amparo del artículo 14 de la Carta de Derechos Fundamentales de 7 de diciembre de 2000, reconocida en el Tratado de Lisboa (artículo 1) que entrará en vigor el 1 de enero de 2009, cuyo texto dice: "Se respetan, de acuerdo con las leyes nacionales que regulen su ejercicio, la libertad de creación de centros docentes dentro del respeto de los principios democráticos, así como el derecho de los padres a garantizar la educación y la enseñanza de sus hijos conforme a sus convicciones religiosas, filosóficas y pedagógicas» (Ibáñez-Martín, 2007, 479).

Ahora bien, desde una perspectiva pedagógica es incuestionable que se trata de entender que el reto es hacer frente a la responsabilidad compartida corporativamente, sin renunciar a las competencias de cada una de las instituciones 
implicadas. Ni los padres son los profesionales de la educación, ni la escuela tiene que suplantar o sustituir la función de la familia. Ni el educando debe dejar de ser agente de su educación. Sociedad civil, familia, Estado y escuela afrontan el reto de la formación, no sólo como una cuestión de hecho, sino como un compromiso de voluntades hacia lo que es valioso en la educación: el desarrollo personal y la convivencia pacífica en la sociedad abierta y pluralista. De tal manera que la solución en la educación no está en elegir en lugar del educando su modo de vida, sino en elegir aquellos modos de intervención pedagógica que garantizan la capacitación del educando para elegir y realizar su proyecto de vida, aprendiendo a construir y usar experiencia para responder a las exigencias del desarrollo cívico en cada situación, de acuerdo con las oportunidades. En perspectiva pedagógica, la educación para la convivencia ciudadana aparece así como un ejercicio de educación en valores orientado al uso y construcción de experiencia axiológica relativa al desarrollo cívico.

Por el hecho de ser una convivencia especificada, el marco legal territorializado adquiere el rango de condición sustantiva en la educación para la ciudadanía como responsabilidad derivada de la formación para la convivencia. Pero, a su vez, por ser una convivencia cualificada, es una responsabilidad compartida con un componente ético de orientación de la acción. De este modo, se evita que la educación para la convivencia ciudadana se convierta en una disciplina dirigida sólo a las relaciones del individuo con el Estado o en una oportunidad propagandista de los estereotipos socio-morales afines al grupo ideológico en el poder. Hay un componente socio-ético en la educación para la convivencia ciudadana, que surge directamente del sentido de responsabilidad compartida y derivada, propiedades de la convivencia pacífica ciudadana. Por una parte, este componente de responsabilidad compartida y derivada aleja este ámbito de formación de una visión parcial orientada, de manera reduccionista, a una educación política o, de manera oportunista, a una educación cívica propagandista. Por otra parte, ese mismo componente de responsabilidad compartida y derivada mantiene vinculada la formación para la ciudadanía a la idea de formación general de educación en valores, respecto de la convivencia pacífica en el marco legal territorializado, que es lo que la hace específica, pero no aislada, a la educación para la convivencia ciudadana.

Si estas reflexiones son correctas, se puede afirmar, por una parte, que el objetivo fundamental de la educación en valores para la convivencia pacífica ciudadana, como tarea, es el desarrollo de destrezas, hábitos, actitudes y conocimientos que capacitan a las personas para estar, moverse, intervenir, actuar, aprender e interrelacionarse pacíficamente con los otros en el marco legal territorializado de derechos y libertades, porque de lo que se trata en la tarea es de construir experiencia axiológica sobre la relación pacífica con el otro en el entorno de derechos y libertades del marco legal territorializado, y también se puede afirmar, por otra parte, que el objetivo fundamental de la educación en valores para la convivencia pacífica ciudadana como resultado es la adquisición en el proceso educativo de un conjunto de competencias que capacitan al educando para decidir y realizar su proyecto, utilizando la experiencia axiológica de relación pacífica con el otro en el 
entorno de derechos y libertades del marco legal territorializado, porque, en definitiva, de lo que se trata respecto del rendimiento es de utilizar esa experiencia axiológica como instrumento de la construcción de uno mismo y de su formación.

\section{A MODO DE CONCLUSIÓN}

Educación en valores, educación intercultural y formación para la convivencia pacífica son tres conceptos que condensan la encrucijada de la intervención educativa en las sociedades abiertas, pluralistas y complejas. El sentido de lo social se ha enriquecido en nuestros días, debido al carácter transnacional de las acciones globales. La interculturalidad, la convivencia, la identidad y los derechos de primera, segunda, tercera y cuarta generación son cuestiones actuales impregnadas de valores y su aprendizaje y la manera de asumirlos y comprometerse con ellos marca el contenido de la educación en su sentido axiológico, que es el sentido más profundo de la educación; es decir, la educación en cuanto cuestión axiológica.

La formación para la convivencia pacífica se configura como ejercicio intercultural de educación en valores: es un ejercicio de elección de valores, nos lleva al reconocimiento y aceptación del otro y nos ejercita en el uso y construcción de experiencia axiológica relativa al reconocimiento de la relación de convivencia con el otro, como ejercicio específico de respeto al límite de elasticidad de la tolerancia, en un espacio convivencial que está constitucionalmente enmarcado.

La educación en valores es una necesidad inexorable y es un reto ineludible que debemos abordar desde estrategias de encuentro, profesional y personal. El conflicto y la confrontación pueden canalizarse mediante el compromiso de voluntades personales e institucionales orientado al desarrollo cívico en un proceso en el que la educación es, cada vez más, el instrumento eficaz de transformación y adaptación del hombre como ciudadano del mundo, pero localizado.

La sociedad civil, el desarrollo cívico y la educación en valores son cuestiones relacionadas, cuyo aprendizaje, junto con la manera de asumir la relación y de comprometerse con ella, marca el sentido más profundo de la educación. Es un reto pedagógico ineludible que debemos abordar con propuestas que no buscan la confrontación, sino la sinergia y la convergencia de líneas de trabajo que identifiquen los sistemas educativos y las comunidades como instrumentos de desarrollo, identidad y diversificación en el marco legal territorializado; es decir, como focos de formación del desarrollo cívico.

La educación para la convivencia ciudadana aparece así como un ejercicio de educación en valores orientado al uso y construcción de experiencia axiológica relativa al desarrollo cívico en un entorno social y personal de interacción, culturalmente diverso. Es obligado en la sociedad abierta y pluralista que el Estado desarrolle el sistema educativo y delimite su competencia en educación en valores. Pero, al mismo tiempo, es obligado que el Estado propicie y garantice el ejercicio de las funciones propias de la sociedad civil, los padres y la escuela en la formación en valores, en general, y en los propios del desarrollo cívico, en particular. 
JOSÉ MANUEL TOURIÑÁN LÓPEZ

EL DESARROLLO CíviCO COMO OBJETIVO. UNA PROPUESTA PEDAGÓGICA

Bibliografía

ARENDT, H. (1974) La condición humana. Barcelona, Seix Barral.

AZnar Minguet, P. (1998) Interacción en contextos educativos; la relación familia-escuela, Revista de ciencias de la educación, 147, 205-216.

BARBer, B. R. (2000) Un lugar para todos. Cómo fortalecer la democracia y la sociedad civil. Barcelona, Paidós.

Barbosa, M. (2008) Educação, cidadania e sociedade civil. Repensando sentidos e articulações em tempos de mudanza, Teoría de la Educación. Revista Interuniversitaria, 20, 45-64.

Benso, C. y Pereira, M. ${ }^{a}$ C. (coords.) (2007) Familia y escuela. El reto de educar en el siglo $X X I$. Universidad de Vigo-Fundación Santa María.

Berger, P. L. y Huntington, S. P. (2002) Globalizaciones múltiples. La diversidad cultural en el mundo contemporáneo. Buenos Aires, Paidós.

Bueno, G. (2006) Zapatero y el pensamiento Alicia. Madrid, Ediciones Temas de Hoy.

Castillejo, J. L. et al. (1994) Teoría de la educación. Madrid, Taurus.

COnSEJO Escolar DEl EsTADO (2001) La convivencia en los centros escolares como factor de calidad. Construir la convivencia. Madrid, MEC.

Delors, J. (ed.) (1996) La educación encierra un tesoro. Madrid, Santillana/UNESCO.

Elzo, J.; Andrés, F.; González-Anleo, J.; González Blasco, L.; Laespada, M. T. y Salazar, L. (2003) Jóvenes españoles 2003. Madrid, Fundación Santa María.

Escámez, J. (2003) Los valores y la educación en España: 1975-2001, en Ortega, P. (ed.). Teoría de la educación, ayer y hoy. Murcia, Seminario Interuniversitario de Teoría de la Educación, 205-237.

EscÁmez, J. y GIL, R. (2001) La responsabilidad en la educación. Barcelona. Paidós.

- (2002) La educación de la ciudadanía. Madrid, CCS-ICCE.

FuENMAYOR, A. (1998) Educación infantil. Costes y financiación. Madrid, Ariel Practicum.

García CARRASCO, J. (2007) Leer en la cara y en el mundo. Barcelona, Herder.

García Carrasco, J. y García del Dujo, A. (1996) Teoría de la educación. Educación y acción pedagógica. Salamanca, Universidad de Salamanca.

García del Dujo, A. (2005) Educación y ciudadanía: reconstrucción del problema en términos de relación, en TOURIÑÁn, J. M. (coord.). Proyecto Educación en valores. ATEI http://www.ateiamerica.com/pages/eduvalores.htm

García Hoz, V. (1970) Principios de Pedagogía sistemática (5. ${ }^{a}$ edición). Madrid, Rialp.

Gervilla, E. (2000) Valores del cuerpo educando. Antropología del cuerpo y educación. Barcelona, Herder.

Giddens, A. (1999) La tercera vía. La renovación de la socialdemocracia. Madrid, Taurus.

Gil Cantero, F. (2008) Ciudadanía y humanidad. La educación en el disenso, Teoría de la Educación. Revista Interuniversitaria, 20, 25-44.

GonzÁlez, P. (dir.) (2006) Jóvenes españoles 2005. Madrid, Fundación Santa María.

HaLLAK, J. (2003) Globalización, derechos humanos y educación, en NúÑEZ, L. y ROMERO, C. (eds.). Evaluación de políticas educativas. Actas del VIII Congreso Nacional de Teoría de la Educación. Universidad de Sevilla, 127-142.

Huntington, S. (2001) El choque de las civilizaciones y la reconfiguración del orden mundial (6. ${ }^{a}$ edición). Buenos Aires, Paidós.

IbáÑeZ-MarTín, J. A. (1975) Hacia una formación bumanística. Objetivos de la educación en la civilización científico-técnica. Barcelona, Herder. 
- (2007) Convicciones pedagógicas y desarrollo de la personalidad de mujeres y varones, Revista Española de Pedagogía, 65 (238), 479-518.

Kuper, A. (2001) La cultura. La versión de los antropólogos. Buenos Aires, Paidós.

LessnofF, M. H. (2001) La filosofía politica del siglo XX. Madrid, Akal.

Mantovani, J. (1972a) Educación y plenitud humana (9. a edición). Buenos Aires, El Ateneo.

- (1972b) La educación y sus tres problemas (9. a edición). Buenos Aires, El Ateneo.

MARín IBÁÑEZ, R. (1976) Valores, objetivos y actitudes en la educación. Valladolid, Miñón.

- (1983) La educación como optimización del hombre, en CAstillejo, J. L. et al. Teoría de la educación I (El problema de la educación). Murcia, Límites, 108-123.

Meil Landwerlin, G. (2006) Padres e hijos en la España actual. Barcelona, Fundación "La Caixa".

Morin, E. (2000) Los siete saberes necesarios a la educación del futuro. Caracas, UNESCOIESALC.

- (2002) ¿Una segunda mundialización?, en Morin, E. et al. Desafíos de la mundialización. Santander, Cuadernos de la Fundación M. Botín (2). Observatorio de análisis de tendencias, $25-40$.

NAssif, R. (1980) Teoría de la educación. Problemática pedagógica contemporánea. Madrid, Cincel.

Naval, C.; Print, M. y Veldhuis, R. (2002) Education for democratic citizenship in the new Europe: context and reform, European Journal of Education, 37 (2), 107-128.

Olveira, E.; Rodríguez, A. y Touriñán, J. M. (2006) Educación para la ciudadanía y dimensión afectiva, en TOURIÑán, J. M. (coord.). Proyecto educación en valores. ATEI http:// ateiamerica.com/pages/educarticulos.htm.

OrTega, P. (2004a) Cultura, Valores y educación: principios de integración, en SEP. La educación en contextos multiculturales: diversidad e identidad. Valencia, 47-80.

- (2004b) La educación moral como Pedagogía de la alteridad, Revista Española de Pedagogía, 57 (227), 5-30.

- (2005) Educación y conflicto, Revista Galega do Ensino, 13 (45), 27-44.

Ortega, P. y Mínguez, R. (2001) Los valores en la educación. Barcelona, Ariel.

- (2003) Familia y transmisión de valores, Teoría de la Educación. Revista Interuniversitaria, 15, 33-56.

Ortega, P.; Touriñán, J. M. y Escámez, J. (2006) La educación ciudadana en una sociedad multicultural y compleja, Revista Portuguesa de Pedagogía, 40 (2), 7-36.

Pérez Alonso-Geta, P. M. ${ }^{a}$ (2007a) El brillante aprendiz. Antropología de la educación. Barcelona, Ariel.

- (2007b) Estudio para determinar los estilos educativos y pautas de interacción en los diferentes tipos de familia (nucleares, monoparentales, reconstruidas, etc.) con hijos/as en el segmento de 6-14 años. Valencia, CICYT. Incie.

Pérez DíAz, V. (1993) La primacía de la sociedad civil. Madrid, Alianza.

- (1996) Sociedad civil: una interpretación y una trayectoria, Isegoria, Revista de Filosofía Moral y Politica, 13, 19-38.

- (1997) La esfera pública y la sociedad civil. Madrid, Taurus.

Pérez Juste, R. (2005) Sociedades multiculturales, interculturalidad y educación integral. La respuesta desde la educación personalizada, Revista Galega do Ensino, 13, 45, 387-415.

Pérez Serrano, G. (1998) Familia y educación. Cuestión a debate, Bordón, 50, 1, 7-20.

Pinillos, J. L. (1978) Lo físico y lo mental, Boletín informativo de la Fundación Juan March, $71,2-37$. 
Puig Rovira, J. M. ${ }^{a}$ (2003) Prácticas morales. Una aproximación a la educación moral. Barcelona, Paidós.

ReBoul, O. (1999) Los valores de la educación. Barcelona, Idea Books.

Rof Carballo, J. (1976) La familia, diálogo recuperable. Madrid, Karpos.

SAlamon, L. M. et al. (2001) La sociedad civil global. Las dimensiones del sector no lucrativo. Madrid, Fundación BBVA.

SARRAMONA, J. (1998) Educación no formal. Barcelona, Ariel Educación.

SAVATER, F. (2002) El valor de educar (16. ${ }^{a}$ edición). Barcelona, Ariel.

SITE (2004) Familia, educación y sociedad civil. Seminario Interuniversitario de Teoría de la Educación. Lugo. (Ver ponencias en Colección Informes e Propostas 14, Santiago de Compostela, ICE de la Universidad de Santiago de Compostela).

Torío, S.; PeÑa, V. y Rodríguez, M. ${ }^{a}$ del C. (2008) Estilos educativos parentales. Revisión bibliográfica y reformulación teórica, Teoría de la Educación. Revista Interuniversitaria, 20, 151-178.

TouRIÑÁn, J. M. (1976) La neutralidad y la educación, Revista Española de Pedagogía, 131, 107-124.

- (1977a) La estimación personal del valor y su sentido pedagógico, Revista de Ciencias de la Educación, 90, 271-282.

- (1977b) La relación libertad-educación, Revista Española de Pedagogía, 136, 179-192.

- (1977c) La formación religiosa en la escuela: su problemática y la contribución de la enseñanza sistemática (I-II), Educadores, 19 (93 y 94), 339-376 y 569-580.

- (1979) El sentido de la libertad en la educación. Madrid, Magisterio Español.

- (1981) Valor pedagógico y educativo del principio de actividad, Revista Española de Pedagogía, 39, 153, 127-142.

- (1987a) Teoría de la Educación. La Educación como objeto de conocimiento. Madrid, Anaya.

- (1987b) El Estatuto del profesorado. Función pedagógica y alternativas de formación. Madrid, Escuela Española.

- (1989) Las finalidades de la educación: análisis teórico, en EsTeve, J. M. (ed.). Objetivos y contenidos de la educación para los años noventa. Málaga, Universidad de Málaga, 15-36.

- (1991) Conocimiento de la educación y función pedagógica: el sentido de la competencia profesional, Teoría de la Educación. Revista Interuniversitaria, 3, 13-27.

- (1995) Exigencias de la Profesionalización como principio del sistema educativo, Revista de Ciencias de la Educación, 164, 411-437.

- (1996) Análisis conceptual de los procesos educativos formales, no formales e informales, Teoría de la Educación. Revista Interuniversitaria, 8, 55-80.

- (1997) La racionalización de la intervención pedagógica: explicación y comprensión, Revista de Educación, 314, 157-186.

- (2001) Acción educativa familiar e intervención pedagógica, en Touriñán, J. M. (ed.). Familia, juventud y nuestros mayores. La actitud proactiva. Santiago de Compostela, Fundación Caixa Galicia, 55-78.

- (2002) Educación y gestión cultural. Exigencias de la competencia técnica, Revista de Educación. Número extraordinario de 2002, 179-198.

- (2003) Sociedad civil y educación de la conciencia moral, Teoría de la Educación. Revista Interuniversitaria, 15, 213-234.

- (2004) Interculturalismo, globalidad y localidad: estrategias de encuentro para la educación, Bordón, 56 (1), 25-47. 
- (2005a) Educación en valores, educación intercultural y formación para la convivencia pacífica, en Touriñán, J. M. (coord.). Proyecto educación en valores. ATEI. http:// ateiamerica.com/pages/educarticulos.htm.

- (2005b) Experiencia axiológica y educación en valores. De la estimación personal del valor, al carácter patrimonial de la elección de valores, Revista Gallego-Portuguesa de Psicología y Educación, 12 (10), 9-44.

- (2005c) Posibilidad y necesidad de la educación en valores, Revista Galega do Ensino, 13 (46), 513-538 y 819-840.

- (2006a) La educación intercultural como ejercicio de educación en valores, Estudios sobre Educación, 10 (junio), 9-36.

- (2006b) Educación en valores y experiencia axiológica: el sentido patrimonial de la educación, Revista Española de Pedagogía, 64 (234), 227-248.

- (2007) Valores y convivencia ciudadana: una responsabilidad de formación compartida y derivada, Bordón, 59 (2-3), 261-311. Fecha publicación, abril de 2008.

- (dir.) (2008a) Educación en valores, sociedad civil y desarrollo cívico. Coruña, Netbiblo.

- (dir.) (2008b) Educación en valores, educación intercultural y formación para la convivencia pacífica. Coruña, Netbiblo.

Touriñán, J. M.; Ortega, P. y Escámez, J. (2006) La educación para la ciudadanía, intrerculturalidad y convivencia en las sociedades pluralistas y abiertas, en TOURIÑÁn, J. M. (coord.). Proyecto educación en valores. ATEI http://ateiamerica.com/pages/ educarticulos.htm.

TOURIÑÁn, J. M. y Rodríguez, A. (1993) La significación del conocimiento de la Educación, Revista de Educación, 302, 165-192.

TOURIÑÁn, J. M. y SÁEZ, R. (2006) La metodología de investigación y la construcción del conocimiento de la educación, Revista Galega do Ensino, 14 (48), 89-130 y 377-410.

VÁzquez Gómez, G. (ed.) (2001) Educación y calidad de vida. Madrid, Editorial Complutense.

Walzer, M. (1993) The civil society argument, en BeIner, R. Theorising Citizenship. Albany, State University of New York Press. 